\title{
Projeto de uma (psico)patologia do sujeito (I): Redefinição do conceito de psicopatologia à luz da questão do sujeito
}

Project of a (psico)pathology of the subject (I): Redefinition of the concept of Psychopathology in light of the question concerning the subject

\author{
Mario Eduardo Costa Pereira*1
}

Este trabalho propõe as bases teóricas para a elaboração de uma nova definição de Psicopatologia, concebendo-a como o estudo dos impasses mórbidos perturbando, ou mesmo impedindo, a realização de um sujeito singular no interior do laço social. A noção de sujeito aqui em questão é aquela decorrente do pensamento psicanalítico de Freud e Lacan.

A (psico)patologia do sujeito apoia-se nas ideias de Viktor von Waizsaecker, para quem a "patologia", diferentemente da noção biológica de "doença", é um fenômeno que pressupõe um sujeito enquanto tal. Inspira-se, igualmente, da obra de Pierre Fédida que sustenta que a psicopatologia se refere fundamentalmente ao pathos subjetivo, em suas múltiplas dimensões semânticas de passividade, sofrimento e paixão.

As consequências da redefinição da (psico)patologia aqui proposta incidem sobre o conjunto das práticas clínicas, sejam elas psicanalíticas, médico-psiquiátricas ou outras, através da especificação ética e técnica do tratamento, agora orientado pelo cuidado com a realização possivel e responsável do sujeito enquanto ser de linguagem, no interior do laço social. Palavras-chave: Sujeito, psicopatologia, psicanálise, psiquiatria

${ }^{* 1}$ Universidade Estadual de Campinas - Unicamp (Campinas, SP, Brasil). 


\section{EPISTEMOLOGIA DA PSICOPATOLOGIA}

No que diz respeito às doenças, eis as circunstâncias a partir das quais formamos um juizo sobre como elas se dão - alcançando a natureza

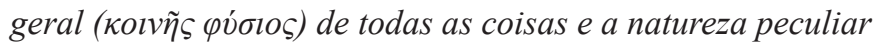

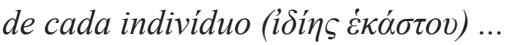

Corpus Hippocraticum, Epidemias I, XXIII

\section{Introdução: apresentação geral de um projeto de (psico)patologia do sujeito}

Este trabalho tem como objetivo propor as bases teóricas para a elaboração de uma nova definição geral de Psicopatologia, doravante concebendo-a como o estudo dos impasses subjetivos perturbando ou mesmo impedindo a realização de um sujeito singular no interior do laço social. Ainda que essa definição não se exprima em um jogo de linguagem próprio às ciências naturais - tal como poderia ser esperado nos dias de hoje de uma proposição de caráter epistemológico referida à "patologia", ela permite avançar na especificação do campo clínico em geral, médico ou não, uma vez que é formulada de modo a orientar ética e praticamente a direção do tratamento e suas finalidades. Dito em outros termos, uma (Psico)patologia do sujeito, como provisoriamente a denominaremos, deverá ser capaz de contribuir de forma significativa e original para a elaboração de uma teoria geral da clínica.

Nossa proposta de redefinição da "psicopatologia", a partir da perspectiva dos impasses de um sujeito tomado enquanto tal, implica algumas consequências importantes que merecem ser explicitadas desde o início, seu detalhamento sendo feito ulteriormente, ao longo deste estudo: 1) a (psico) patologia, assim compreendida, sem qualquer referência ao âmbito da Natureza (physis), constitui um campo epistemológico autônomo em relação à Biologia, à Psiquiatria e à própria Medicina em geral; 2) sob essa perspectiva, ela se inscreve na visada jasperiana, segundo a qual a psicopatologia constitui uma disciplina autônoma, que fornece os fundamentos teóricos para o exercício da clínica psiquiátrica. Mas nossa definição também a prolonga, na medida em que suas consequências se estendem sobre todas 
as práticas clínicas em geral e não apenas em Psiquiatria; 3) o fato de nossa abordagem da (psico)patologia ser exterior ao campo da physis não implica, no entanto, que ela se oriente para uma dimensão supostamente psíquica, ou mesmo psicogênica, da patologia. Ao contrário, recusamos de antemão todo dualismo nessa questão. Levada às suas últimas consequências, nossa proposição faz com que o próprio termo "psicopatologia" se torne, em certa medida, redundante e obsoleto, podendo ser substituído com vantagens pelo conceito mais simples e preciso de "patologia", sobre o qual nossa redefinição incidiria de maneira mais apropriada. Se toda a psicopatologia se refere, em última instância, às vicissitudes do pathos de um sujeito singular, qual então o sentido de duplicarmos a referência à subjetividade pela evocação de uma noção tão profundamente marcada pelo dualismo cartesiano, como a de "alma" (psyche) ou psiquismo? Não teria sido justamente essa a fonte de muitos dos impasses teóricos fulcrais com os quais até hoje se debatem os estudos visando a delimitação formal do "objeto psicopatológico"?

O projeto de uma (psico)patologia do sujeito deverá, portanto, conduzir a uma nova maneira de conceber e definir "Patologia", momento em que aquela se revelaria apenas como ponte epistemológica provisória e historicamente datada, mas necessária, para se atingir esse objetivo. Retomaremos essa proposição mais adiante. Por enquanto, é suficiente assinalar que essa é a razão pela qual grafamos o radical "psico" entre parênteses em nossa escrita de (psico)patologia.

Ainda que não recorra a uma linguagem naturalista, nossa proposição não tem necessidade de negar uma definição biológica de "doença", nem a pertinência do recurso às ciências naturais nos campos essencialmente práticos da clínica e da terapêutica. O que ela rejeita é a ideia de que a disfunção orgânica e a busca linear de sua correção no plano biológico constituam os elementos fundantes, supostamente autoevidentes, capazes de orientar por si sós a direção e os objetivos do tratamento. Se concebemos que qualquer projeto terapêutico encontra sua justificativa ética e sua orientação técnica no cuidado (therapeia, $\theta \varepsilon \rho \alpha \pi \varepsilon i ́ \alpha)$ com os impasses mórbidos comprometendo a realização possível de um sujeito tomado enquanto tal, então a própria nosologia deverá ser abordada, no contexto clínico, a partir de sua incidência específica no campo subjetivo singular. Trata-se de um salto do nível da disfunção orgânica para o registro propriamente humano, estabelecido pela dimensão simbólica e social da linguagem, a qual confere ao fenômeno mórbido de natureza biológica sua densidade especificamente (psico)patológica.

Nesse sentido, nossa proposta permanece alinhada com a tradição hipocrática, segundo a qual a Medicina e todas as práticas clínicas dela 


\section{EPISTEMOLOGIA DA PSICOPATOLOGIA}

derivadas necessitam da ciência para operar, mas não se definem por serem elas próprias "ciências da cura". Ao contrário, é preciso recordar que a partir do século VI a.C., a linhagem médica dita de Hipócrates constitui a Medicina

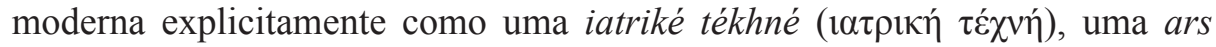

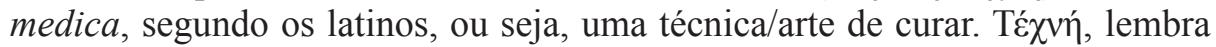
Heidegger, "não constitui apenas a palavra do fazer na habilidade artesanal, mas também do fazer na grande arte e das belas-artes. A $\tau \dot{\chi} \chi v \eta ́$ pertence

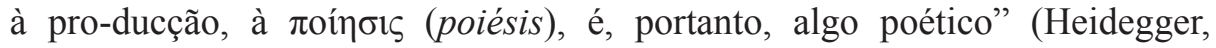
1953/2002, p. 17). Sob essa perspectiva, no coração mesmo da tecnicidade própria à Medicina, a ação especificamente médica define-se como ato criativo, visando aplicar, segundo a arte, ${ }^{1}$ os conhecimentos gerais da ciência da physis a serviço do tratamento da condição patológica necessariamente única de cada paciente. É esse gap lógico entre o geral das ciências da natureza e o idiossincrático da patologia de cada um, que faz do ato médico algo de lógica e eticamente irredutível à mera aplicação mecânica de um algoritmo de conhecimentos universais (cf. Pereira, 2017).

Ao longo de sua história, contudo, produziu-se culturalmente o esquecimento da arché ( $\alpha \rho \chi \eta ́)$, desse princípio fundante e sempre presente da Medicina como arte médica - muitos o assinalaram e delimitaram, a começar pelo próprio filósofo da Floresta Negra - reduzindo a técnica à sua dimensão meramente instrumental.

Originalmente, as raízes pitagóricas da medicina hipocrática orientavam a arte de curar não tanto como tratamento direto das doenças, concepção que só se tornaria hegemônica na medicina ocidental a partir do século XVII (cf. Feys, 2009), mas antes como (re)instalação do equilíbrio do indivíduo, colocando-o em harmonia com a ordem do Cosmos. ${ }^{2}$ A teoria dos humores,

1 “...para tratar al enfermo katà tékhnén, según arte, [el médico hipocrático] debe proceder como luego dirá Aristóteles que es regla en el tekhnités: sabiendo por qué hace aquello que hace; [...]. De otro modo él no pasaría de ser un vulgar y rutinario empeirós. El hipocrático comienza a ser médico poniendo en ejercicio su logos frente al oculto y a veces secreto logos de la naturaleza" (Entralgo, 1970, p. 226).

${ }^{2}$ Sobre o papel decisivo da noção de 'harmonia' e de suas incidências ao mesmo tempo ontológicas e cósmicas, Werner Jaeger, tratando do uso da dietética e da ginástica pela medicina hipocrática, afirma: "A cultura física, tal qual os médicos e os ginastas gregos a concebem, é também algo de espiritual. Incute ao Homem, como norma suprema, a rigorosa observância do nobre e são equilíbrio das forças físicas. E como a igualdade e a harmonia constituem a essência da saúde e de toda perfeição física 
referente teórico fundamental para a atividade médica dos gregos, implicava que, para além da doença, o clínico fosse capaz de diagnosticar e tratar os desequilíbrios singulares de cada paciente, situados à base da enfermidade, permitindo assim que a própria Natureza colocasse em operação seus dispositivos de cura e de restauração. Era assim que a "arte" do médico

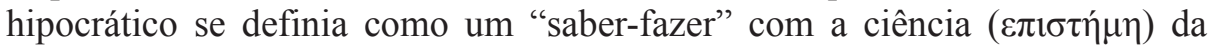

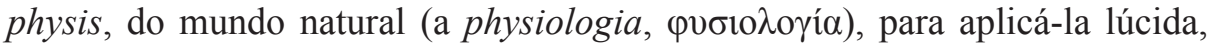
concreta e eficazmente no campo da therapeia $(\theta \varepsilon \rho \alpha \pi \varepsilon i ́ \alpha)$ de um indivíduo singular. O ı $\alpha \tau$ pó $\varsigma$ grego operava, pois, servindo-se da ciência para intervir de forma efetiva sobre um plano que é a ela irredutível: o das existências humanas únicas e reais de seus pacientes. Nisso consistia sua arte ( $\tau \varepsilon \dot{\chi} \chi \eta \dot{)})$ e sua obra $(\varepsilon \rho \gamma \omega v)$. É isso também o que evoca a passagem do Corpus Hippocraticum escolhida como epígrafe deste artigo.

Se retomamos, ainda que de maneira incidental, esses fundamentos gregos da tradição clínica é na tentativa de produzir sobre o leitor um

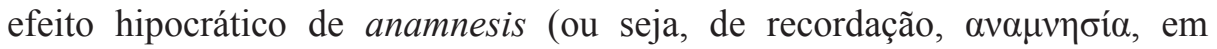
seu sentido forte de implicação afetiva e existencial com o rememorado) e, assim, nele suscitar a reflexão sobre o que se ganhou e o que se perdeu nessa transformação histórico-cultural do sentido originário da $\tau \varepsilon ́ \chi v \eta ́$, pela qual a ênfase maciça nas ciências médicas promove o progressivo esquecimento da arte própria à Medicina.

Rompendo com a concepção intuitiva e tradicional de psicopatologia como disciplina científica destinada a descrever os transtornos mentais em suas manifestações objetivas e subjetivas, a explicar seus mecanismos causais e a compreender seus eventuais nexos psicológicos, o que se visa aqui é redesenhar o campo do patológico como relativo às condições que perturbam ou mesmo tornam impossível a realização de um sujeito singular enquanto tal, no interior do laço social. Claro está, portanto, que nossa perspectiva não nega a especificidade epistemológica de disciplinas como a semiologia psiquiátrica, a nosografia e a nosologia dos transtornos mentais. O que ela recusa é confundi-las, formal e epistemologicamente, com a (psico)patologia.

Segundo nossa perspectiva, a existência de uma doença, no sentido de perturbação do design fisiológico mais eficiente para a execução de uma

em geral, o conceito de são é ampliado até formar um conceito normativo universal aplicável ao mundo e ao quanto nele vive, visto serem as suas bases a igualdade e a harmonia, as potências que [...] criam o que é bom e justo em todos os níveis da vida..." (Jaeger, 1995, p. 1059) 


\section{EPISTEMOLOGIA DA PSICOPATOLOGIA}

função biológica da espécie, conforme a clássica definição naturalista proposta por Boorse (1977), ${ }^{3}$ à qual retornaremos mais adiante, não delimita por si mesma a incidência propriamente patológica no campo do sujeito singular. De modo correlativo, a ausência de doença biologicamente definida não exclui a existência de uma condição patológica do ponto de vista dos impasses ou impedimentos da realização subjetiva. Mesmo assim, um e outro desses casos de figura constituem motivos que levam um sujeito a buscar assistência médico-clínica. Por fim, a condição especificamente (psico)patológica não pode ser confundida com a incompletude estrutural e constituinte da condição humana, expressa em dimensões como a finitude, a temporalidade, a fatuidade, a abertura ao mundo e à contingência e a incidência humanizante da linguagem, com o correlativo desamparo que esta evidencia quanto à falta de garantias últimas no que se refere aos fundamentos do mundo e ao próprio sentido da existência. A essas dimensões próprias ao humano, enquanto ser de linguagem, chamaremos de "condição pática do sujeito", devendo ser teórica e clinicamente distinguida de seus impasses propriamente "patológicos", sempre contingentes e dependentes da posição subjetiva.

A patologia, assim definida, é, portanto, um fenômeno que incide necessariamente sobre um sujeito, ou seja, em um ser constituído enquanto tal pela linguagem e por sua inserção simbólica do laço social. Mesmo seu inegável e inseparável fundamento biológico - a que chamaremos "organismo" só se coloca no campo da patologia, em um sentido próprio, através de sua captura pela linguagem, com tudo aquilo que esta implica das dimensões de singularidade, de alteridade, de sexualidade, de sofrimento e de morte. É nesse plano, a que chamaremos de "corpo", que incide a "patologia", como fenômeno que atinge um sujeito enquanto tal. É sobre o sujeito corporalmente encarnado que operam, em última instância, ética e tecnicamente todas as diferentes formas de prática clínica, compartilhando entre elas aquilo que no dizer de Lacan constitui o fundamento e a orientação moral última de qualquer forma de tratamento: "melhorar a posição do sujeito". 4

3 “" [...] diseases are internal states that depress a functional ability below species -typical levels. Health as freedom from disease is then statistical normality of function, i.e., the ability to perform all typical physiological functions with at least typical efficiency. This conception of health is as value-free as statements of biological function" (Boorse, 1977, p. 542).

4 "Il est bien certain que notre justification comme notre devoir est d'améliorer la position du sujet" - J. Lacan, Seminário 10, sessão do 12 de dezembro de 1962. 
A releitura que aqui propomos do campo (psico)patológico deverá, portanto, ser capaz de responder de maneira mais apropriada às inúmeras dificuldades decorrentes do emprego de noções como "doença" ou "transtorno" mental para especificar o objeto da psicopatologia (sobre a questão da "psiquiatria centrada no diagnóstico", remetemos a Pereira, 2014). Estas não são rejeitadas em si próprias, mas consideramos que seus campos de pertinência são os da nosologia e da nosografia (no caso, "psiquiátricas"), devendo o termo (psico)patologia permanecer reservado à dimensão específica de perturbação no âmbito do sujeito e, portanto, necessariamente idiossincrática. A idiossincrasia, sob essa ótica, não seria concebida como desvio em relação a uma suposta normalidade ideal e generalizável. Ela é a própria condição definidora do sujeito enquanto ser de linguagem e de fala (sob suas mais diversas modalidades). Sua singularidade, como caso concreto sobre o qual opera a clínica, não decorre apenas do caráter único de sua constituição biológica. Ela decorre, em primeiro lugar, do fato de que a linguagem, enquanto fenômeno simbólico (logo, social), designa, constitui e reconhece especificamente cada um, através do estabelecimento do contraste lógico e diferencial daquele sujeito em relação a todos os demais.

Dessa forma, "nosologia", no sentido estrito que aqui propomos, deve ser concebida como um termo técnico que se refere especificamente aos fenômenos biológicos mórbidos do organismo, passíveis de abordagem científica em um sentido estrito. "Patologia", por sua vez, refere-se a um sujeito, enquanto ser de linguagem e de fala, existindo corporalmente.

A condição especificamente (psico)patológica não decorre, portanto, de maneira direta do caráter único e peculiar do sujeito, mas do impasse ou impossibilidade deste em se apropriar de sua própria idiossincrasia, assumindo-a existencialmente em conformidade com seu próprio desejo, e segundo uma modalidade de negociação compatível com a manutenção de sua inscrição responsável no interior do laço social, ou seja, levando em consideração subjetiva e eticamente a dimensão da alteridade.

Dessa forma, se falamos de uma "(psico)patologia do sujeito" não o fazemos visando especificar uma modalidade especial de psicopatologia, mas como um recurso apenas provisório, até que sejamos capazes de demonstrar que o pathos a que se refere qualquer patologia implica necessariamente, para além da eventual disfunção fisiológica ou da vivência subjetiva (Erlebnis) de sofrimento, os impasses de um sujeito único, em seus esforços de realização possível. Como veremos, "sujeito", "idiossincrasia" e "patologia" são termos indissociáveis. Eles decorrem, desde um ponto de vista exclusivamente lógico e formal, não da realidade biológica frágil e 


\section{EPISTEMOLOGIA DA PSICOPATOLOGIA}

mortal do homem, mas do fato de que o humano se constitui, enquanto tal, por sua inscrição no campo simbólico, erótico e social da linguagem. Nesse sentido, enquanto ser de linguagem, todo homem padece, incuravelmente, de sua condição humana. Esta constitui, a nossos olhos, sua condição "pática". Sob essa mesma perspectiva - e por contraste - a "patologia" é um estado contingente, decorrente dos impasses do sujeito em encontrar, diante de certas circunstâncias, formas satisfatórias para sua realização.

Diferentemente da Psicopatologia Geral de Jaspers, e de maneira mais abrangente do que a expressa nesse célebre tratado, a (psico)patologia do sujeito não se restringe aos fenômenos ditos "patológicos" — pelo menos no sentido estritamente médico proposto a este termo pelo autor alemão devendo ser capaz de descrever como patológicas as condições de impasse na realização do sujeito, provisoriamente melhor descritas pelas expressões "existência malograda", cunhada por Binswanger (1956/1977), ou mesmo de "vida contrariada", proposta por Canguilhem (1966/1991). Será na visão proposta por Viktor von Weizsaecker (1956/2011) — e resgatada por Henry Maldiney (1961) e por Pierre Fédida (1998) — segundo a qual a noção de "patologia" refere-se necessariamente a um sujeito, e na concepção psicanalítica de "sujeito", decorrente dos pensamentos de Freud e Lacan, que nossa definição de (psico)patologia como impasse mórbido da realização subjetiva singular encontrará seu assentamento teórico específico. $\mathrm{O}$ eventual sucesso desse projeto implicará, dessa forma, a elaboração de uma ética da clínica (médica e outras) compatível com a ética do sujeito e de seu desejo, própria à psicanálise (Lacan, 1959-1960/1988).

Não se trata, pois, da proposta de construção de uma nova psicopatologia psicanalítica, mas de nos servirmos de uma concepção psicanalítica de sujeito e de seus impasses específicos para descrevermos sua dimensão propriamente patológica e como esta se manifesta concretamente nos fenômenos clínicos. Em consequência, singularidade, diferença, o desejo e suas vicissitudes e as diferentes modalidades de constituição e inscrição do sujeito no laço social serão parâmetros psicanalíticos fundamentais para a delimitação da (psico) patologia do sujeito tal como aqui a concebemos.

A clínica que dela decorre consiste na construção das condições de possibilidade para a emergência e reconhecimento do sujeito em sua peculiaridade, na identificação de seus impasses patológicos como norteadores da direção do tratamento e, no plano terapêutico, no emprego técnico de meios biológicos, psicológicos, psicanalíticos e/ou outros, conforme o caso, em vista da (re)conciliação do sujeito com os processos de realização possível de sua singularidade no interior do laço social. Aqui, a palavra, sua escuta e a 
interpelação do paciente no plano específico de sua verdade subjetiva ocupam papel central. Correlativamente, a explicitação de uma matriz ética comum permitirá à psicanálise, à medicina, em particular à psiquiatria, e a qualquer outra modalidade de prática da therapeia de, mantendo suas especificidades técnicas, operarem clinicamente de maneira mais concertada, coerente e eficaz.

\section{Plano de exposição do projeto de uma (psico)patologia do sujeito}

Nosso projeto de uma (psico)patologia do sujeito será apresentado em duas etapas, o presente artigo constituindo a primeira delas. Um segundo trabalho completará a exposição geral dessa proposta.

A partir da introdução acima realizada, buscaremos aqui delinear a ruptura específica que nossa redefinição de "(psico)patologia", à luz da questão do sujeito, produz sobre a concepção médico-psiquiátrica tradicional relativa a essa disciplina tão fundamental para todas as práticas clínicas voltadas para o cuidado com o padecimento psíquico. Veremos como a linguagem, em sua dimensão a um só tempo simbólica e social, desnaturaliza tanto o chamado "transtorno mental" como o campo mais amplo da própria "Patologia". Para isso, serão examinadas as concepções hegemônicas de "Psicopatologia" no âmbito da psiquiatria, bem como as formas pelas quais os fenômenos dito psicopatológicos se inscrevem e se especificam no universo teórico da "patologia" médica. Examinaremos as tensões entre as propostas mais naturalistas de definição de "psicopatologia" e aquelas de cunho mais humanista, oriundas sobretudo da fenomenologia, da psicanálise e da análise existencial. Por fim, mostraremos como as contribuições de autores como Freud, Binswanger, Viktor von Weizsaecker, Erwin Strauss, Henri Maldiney, Roland Kuhn, Pierre Fédida e Jacques Schotte contribuíram de forma decisiva para um questionamento mais radical do pathos de que tratam a Medicina, a Psiquiatria e a Psicopatologia, abrindo a possibilidade de se conceber e recentralizar o campo do (psico)patológico em torno do sofrimento e dos impasses próprios ao sujeito.

Em um segundo artigo, examinaremos a maneira pela qual uma concepção psicanalítica de "sujeito" decorrente das obras de Freud e de Lacan permitiria superar certos impasses éticos, epistemológicos e clínicos emergentes da tradição psiquiátrica da psicopatologia. Tendo como subtítulo "o sujeito da (psico)patologia", esse trabalho examinará mais em detalhes 


\section{EPISTEMOLOGIA DA PSICOPATOLOGIA}

o conceito de "sujeito", as grandes linhas pelas quais ele constitui uma noção crítica na história do pensamento e a maneira como aparece de forma implícita ou abertamente tematizado na tradição psicopatológica. Buscaremos demonstrar a ruptura específica que a psicanálise, a partir de Freud, introduz no campo do sujeito e da subjetividade, tão decisivo para a psicopatologia. $\mathrm{O}$ objetivo central desse artigo será, pois, o de justificar teórica e eticamente, a partir da psicanálise, a definição de (psico)patologia como disciplina que se ocupa das condições contingentes conduzindo a impasses ou a impedimentos da realização do sujeito, enquanto tal, no interior do laço social. Por fim, esse estudo abordará as consequências de se tomar uma (psico)patologia do sujeito como referência epistemológica e ética para o estabelecimento da direção e das finalidades do tratamento nas práticas clínicas em geral, e não apenas naquelas especificamente psiquiátricas.

\section{Da patologia médica e à psicopatologia geral}

No contexto contemporâneo, a acepção médica de "patologia" remete de forma quase espontânea ao âmbito da biologia e das ciências naturais em geral, enquanto estudo descritivo e explicativo-causal das doenças. Já em sua Introduction à l'étude de la médecine expérimentale (1865), por exemplo, Claude Bernard se refere à patologia como "la connaissance des maladies et des causes qui les déterminent” (p. 8). Nesse jogo de linguagem causalista próprio à biomedicina, a doença biologicamente definida desempenha o papel de norte, de orientador racional e ético da prática médica. Nele, a clínica teria como ponto de partida o diagnóstico preciso da condição patológica, logo de um mal objetivo (ou operacionalmente objetivável, como é o caso de classificações do tipo do DSM) de natureza biológica, do qual decorriam de forma quase necessária - e idealmente mecânica, uma vez que movida por saberes objetivos, validados pelo método científico — os procedimentos técnicos empregados com vistas à sua recuperação completa (cura) ou parcial, à readaptação e à prevenção. Compreende-se assim que a patologia, definida como fenômeno natural de caráter prejudicial para os interesses de sobrevivência, reprodução e bem-estar do indivíduo ou da espécie, desempenhe um papel referencial central na estrutura lógica e moral da ação clínico-terapêutica. Nosso objetivo nesse projeto, coerente com o argumento até aqui desenvolvido, é o de distiguir de forma clara o plano das disfunções fisiológicas, biologicamente prejudiciais para o indivíduo e/ ou para a espécie, de suas incidências em um sujeito humano enquanto tal, ou 
seja, constituído como ser marcado pela linguagem e da dimensão simbólica constitutiva do laço social. Ao primeiro reservaremos a noção de "nosologia". Correlativamente, o termo "patologia" deverá ser reservado, em nossa (psico) patologia, ao plano específico dos impasses do sujeito em suas possibilidades de realização singular, ligados ou não, direta ou indiretamente, aos fenômenos biológicos da doença e da disfunção. Mais explicitamente, a patologia não decorre de maneira linear da nosologia, podendo inclusive prescindir desta para se constituir enquanto tal.

Examinemos, agora, de que maneiras, no âmbito da psiquiatria, a patologia se especifica como "psicopatologia", no sentido médico-psiquiátrico tradicional.

A maioria dos autores considera que "Psicopatologia" é um neologismo forjado em meados do século XIX, visando desde o início um uso técnico no âmbito da psiquiatria. Segundo German Berrios (2016), o termo composto Psycho-pathologie apareceu pela primeira vez em 1845 em um livro de Feuchtersleben intitulado Lehrbuch der ärztlichen Seelenkunde. Seu emprego teórico sistemático, contudo, só se daria efetivamente em 1878 com o médico alemão Hermann Emminghaus em seu tratado Allgemeine Psychopathologie zur Einführung in das Studium der Geistesstörungen (Psicopatologia geral para introdução ao estudo de distúrbios mentais). Berrios sustenta que "Karl Jaspers pegou emprestado de Emminghaus o nome para seu próprio livro, cuja primeira edição foi publicada em 1913" (Berrios, 2016, p. 305).

O sentido vasto que Emminghaus dá a Psychopathologie faz com que esse termo recubra praticamente todo o campo da psiquiatria clínica. É somente com Störring (cf. Berrios, 2016) e posteriormente com Chaslin ${ }^{5}$ (1912) e Jaspers (1913/1979) que essa palavra passa a ser empregada com uma conotação mais próxima ao uso contemporâneo, dando "ênfase nos próprios sintomas mentais, na dinâmica de sua construção e no seu papel na formação histórica das doenças mentais" (Berrios, 2016, p. 305). Essa origem médico-psiquiátrica de "psicopatologia" traria correlativamente o desafio da delimitação teórica do tipo específico de "patologia" do qual deveria se ocupar o novo campo científico.

5 “... je suis loin de penser que l'observation pure soit le dernier recours de la médecine mentale; ce n'en est que le premier, en attendant mieux: la pathologie mentale." (“... estou longe de pensar que a observação pura é o último recurso da medicina mental; é apenas o primeiro, enquanto espera melhor: a patologia mental"; tradução livre de minha autoria). Chaslin, 1912, p. VII. 


\section{EPISTEMOLOGIA DA PSICOPATOLOGIA}

Em seu célebre tratado Psicopatologia Geral, Karl Jaspers (1913/1979) descreve o objeto formal da disciplina em uma passagem bastante conhecida:

O objeto da psicopatologia é o fenômeno psíquico realmente consciente. Queremos saber o que os homens vivenciam e como o fazem. Pretendemos conhecer a envergadura das realidades psíquicas [seelischen Wirklichkeiten]. E não queremos investigar apenas as vivências humanas [das Erleben der Menschen] em si, mas também as condições e as causas [die Bedingungen und Ursachen] de que dependem os nexos em que se estruturam, as relações em que se encontram, e os modos em que, de alguma maneira, se exteriorizam objetivamente. Mas nem todos os fenômenos psíquicos constituem nosso objeto. Apenas os "patológicos" [sondern nur das ,pathologische“ ist unser Gegenstand]. (p. 13)

Explicita-se assim a perspectiva específica da psicopatologia jasperiana: a descrição da vivência subjetiva e consciente (Erlebnis) que experimenta o paciente em seu estado mental patológico, suas causas, conexões de sentido (e sua eventual ruptura) no interior da curva vital do indivíduo e as maneiras pelas quais essa condição psíquica mórbida se manifesta objetivamente.

No contexto da Allgemeine Psychopathologie, a "Psicopatologia" qualifica-se de "Geral" na medida em que visa aquilo que é generalizável nas experiências subjetivas da patologia mental. Ainda que se interesse de maneira maior e explícita pela vivência subjetiva, não se trata de forma alguma, para Jaspers, de estudar a patologia mental sob a perspectiva do sujeito singular. $\mathrm{O}$ grande psicopatólogo alemão assume a perspectiva dos elementos "generalizáveis" da experiência psíquica da patologia mental já na primeira página de seu tratado, mesmo reconhecendo de antemão a tensão lógica entre o geral da ciência e o particular implicado na clínica concreta:

A prática da profissão psiquiátrica se ocupa sempre do indivíduo humano todo (...). Aqui, todo o trabalho se relaciona com um caso particular. Não obstante, para satisfazer as exigências decorrentes dos casos particulares, o psiquiatra lança mão, como psicopatólogo, de conceitos e princípios gerais. Na profissão é uma pessoa viva que compreende e atua. Para ele a ciência é apenas um dos meios de auxílio. Enquanto para o psicopatologista a ciência é um fim em si mesma. Ele quer apenas conhecer e reconhecer, caracterizar e analisar, mas não o indivíduo e sim o Homem. (Jaspers, 1913/1979, p. 11)

Dito em outros termos, a psicopatologia, aos olhos Jaspers, é um conhecimento científico abstrato cuja eficácia no campo clínico depende da arte, no sentido da tecknè grega, do médico ao empregá-la junto a seu paciente. 
Essa tomada de posição teórica jasperiana nos permite, por contraste, especificar uma dimensão importante de nosso próprio projeto de uma (psico) patologia do sujeito. Ao cotejarmos a perspectiva de Jaspers com a passagem do Corpus Hippocraticum, trazida em epígrafe deste artigo, constatamos que a Allgemeine Psychopathologie se ocupa apenas da primeira cláusula do texto grego, relativa ao conhecimento das doenças (voбท́ $\mu \alpha \tau \alpha)$ : a que se refere ao

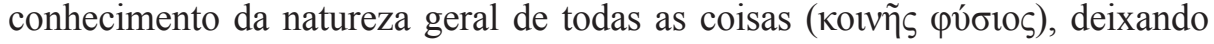
metodologicamente de lado, enquanto ciência (mas não sem reconhecer sua importância decisiva nos planos clínico e filosófico), a natureza peculiar de

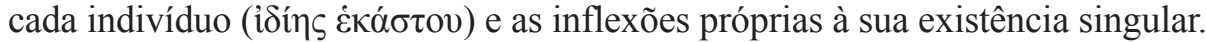

Sobre esse tópico, contudo, é necessário avançarmos com prudência. Stanghellini, por exemplo, considera que a ideia de que o verdadeiro conhecimento só se estabelece a partir da consciência crítica dos limites do conhecimento é basilar para o pensamento jasperiano, dela decorrendo uma postura ao mesmo tempo ética e metodológica para sua psicopatologia - a de que o caráter aberto da existência humana não pode ser artificialmente suturado pela teoria ou pelo saber científico: "Neither philosophy nor science can provide a full knowledge of man as a whole. All determinate knowledge shows its limitations when faced with the breadth of human existence" (Stanghellini, 2013, p. 171). Guilherme Messas (2014), por sua vez, mostra com pertinência o caráter propedêutico da referência ao "geral" na psicopatologia de Jaspers. Evocando uma decisiva passagem da Allgemeine Psychopathologie, "O homem é incompleto em sua essência e inacessível em si mesmo ao conhecimento" (Jaspers, 1959a, p. 625), Messas argumenta que a perspectiva jasperiana toma o cuidado de manter a questão da "totalidade" da existência humana - que deve justamente situar-se em relação à sua incompletude fundante - como um tema especificamente filosófico, não sendo elucidável enquanto tal no plano empírico-experimental da ciência.

Identificamos, assim, duas orientações fortes no pensamento psicopatológico de Jaspers: de uma parte, o reconhecimento da insuperável impossibilidade de a ciência dar conta integralmente do Homem; de outra, uma postura implicitamente aristotélica quanto ao estatuto epistemológico que atribui à Psicopatologia: só existe ciência do Geral.

De modo a explicitar a tensão constitutiva entre o caráter idealmente universal das proposições científicas e a singularidade irredutível de cada caso concreto, examinemos mais em detalhes a maneira pela qual a iatriké tékhné da medicina hipocrática é explicitamente convocada por Aristóteles como referência para a construção de sua Lógica e para sua argumentação relativa às aplicações técnicas. 


\section{Sobre as referências às categorias lógicas de Geral e de Singular na definição de "Psicopatologia"}

No Livro I (Alpha) de sua Metafísica, Aristóteles tratará das relações entre as categorias lógicas do "universal" e do "singular" apoiando-se justamente em exemplos oriundos da tekhné médica e, assim como Jaspers, distinguindo com rigor o conhecimento relativo a um indivíduo concreto daquele referido à abstração geral do "Homem":

Em relação ao agir, a experiência parece não ser diferente da técnica [ $\tau \dot{\varepsilon} \chi v \eta \zeta]$, pois, pelo contrário, os experientes têm mais sucesso do que aqueles que, sem

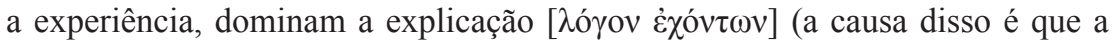

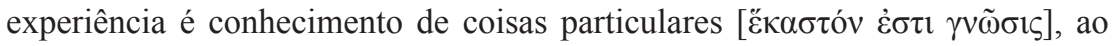
passo que a técnica [ $\tau \dot{\varepsilon} \chi v \eta \zeta]$ é conhecimento de universais, e todas as ações

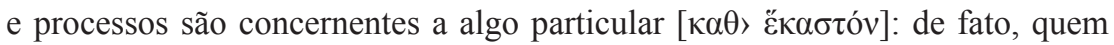
medica não cura o Homem [ảv $\theta \rho \omega ́ \pi \omega]$, a não ser por concomitância, mas cura Cálias, Sócrates ou algum outro que se denomina deste modo, ao qual sucede como concomitante ser homem; assim, se alguém, sem experiência, tiver uma explicação, e se conhecer o universal, mas ignorar o particular nele incluído, muitas vezes poderá cometer erros em seus curativos, pois é o particular que é curável). (Aristóteles, 2008, 981a 12, p. 10)

Assim, já em Aristóteles explicita-se a paradoxal irredutibilidade da clínica à ciência: o exercício da Medicina segundo a arte não é possível sem o recurso à ciência, contudo a ciência se refere a categorias universais abstratas, enquanto a tekhné médica se exerce concretamente sobre pacientes reais, únicos. A dimensão propriamente criativo-poética do fazer médico reside, portanto, pelo menos em parte, em sua capacidade de colocar seu saber sobre a physis a serviço do tratamento da patologia de um paciente específico e, como tal, necessariamente idiossincrático, definindo-se como exceção a qualquer generalização absoluta a que se possa querer submetê-lo. Outras dimensões da arte especificamente médica decorrem, como veremos, em sua habilidade de escuta do paciente no nível de sua própria idiossincrasia (anamnese) e, tal como o indica o médico Erixímaco no Banquete, de Platão, na capacidade do iatros ( $\gamma 1 \alpha \tau \rho$ ó $\varsigma$ ) grego em identificar Eros doente no interior da patologia: " $E$, com efeito, a medicina, para falar em resumo, a ciência dos fenômenos de amor, próprios ao corpo" (Platão, 1991, p. 28).

Ou seja, a medicina hipocrática supõe - e deve dela se ocupar — da incidência da erótica própria ao corpo e ao padecimento do paciente. Dessa forma, em grande medida, a ética e a condução técnica das práticas médica e 
psiquiátrica dependerão da concepção que se tenha do pathos a que se referem os conceitos fundamentais de "patologia" e de "psicopatologia".

\section{O pathos grego: da filosofia à (psico)patologia, passando pela medicina}

Apesar de sua forte conotação médica atual, o termo "patologia" é tributário da vasta rede semântica recoberta pelo radical grego pathos, amplamente empregado desde a Grécia Antiga tanto na língua comum quanto em áreas tão diversas como a filosofia, a poética, a retórica e a tragédia, além, é claro, da própria medicina hipocrática.

Muito já se falou sobre o caráter problemático da redução do pathos grego ao registro estritamente médico de "doença", enquanto disfunção biológica mórbida e prejudicial à sobrevivência do indivíduo e da espécie. Heidegger, contudo, propõe o resgate arqueológico dos sentidos originais dessa palavra encontrando-a como termo fundante da própria filosofia já nos escritos de Platão e de Aristóteles.

Em sua célebre conferência de agosto de 1955, pronunciada em francês 842 em Cérisy-La-Salle e intitulada Qu'est-ce que la philosophie?, Heidegger trataria minuciosamente do âmbito semântico originário recoberto pelo pathos grego. ${ }^{6}$ Seu interesse por esse termo advém do uso que dele faz Platão para designar nada menos que a modalidade especificamente grega de disposição existencial face ao ser, que tornou possível o surgimento da filosofia: o espanto (thaumadzein). Para Heidegger, "a arkhé da filosofia é o pathos do espanto" e é graças a esse pathos específico, à disponibilidade do homem grego, sua abertura, em se deixar espantar pela epifania do "ente no ser", que se tornou possível a filosofia:

O thaumadzo (espanto ou admiração) é atestado como princípio (arkhé) da filosofia por Platão e Aristóteles. Primeiramente, Platão (no Teeteto 155d) afirma: "É verdadeiramente de um filósofo esse pathos — o espanto (thaumadzein); pois não há outra origem imperante (arkhé) da filosofia do que este" [mala gar philosophou touto to pathos, to thaumazein, ou gar alle arkhe philosophias he haute]. E Aristóteles (na Metafísica A 2, 982b 12ss) confirma o dito de Platão: "Pelo espanto, os homens chegaram agora e chegaram

${ }^{6}$ Sobre a leitura heideggeriana do termo grego "pathos", remetemos a (Martins, 1999). 


\section{EPISTEMOLOGIA DA PSICOPATOLOGIA}

antigamente à origem imperante do filosofar" [dia gar to thaumazein hoi anthropoi kai nyn kai proton erxanto philosophein]. (p. 37)

É assim que o autor de Ser e Tempo traduzirá, de forma surpreendente, o pathos grego por um termo alemão igualmente muito caro à tradição psicopatológica, o de Stimmung, a disposição, o humor, a tonalidade de sintonia da abertura do Dasein para o mundo e para a contingência do acontecimento.

Traduzimos habitualmente páthos por paixão, turbilhão afetivo. Mas páthos remonta a páskhein, sofrer, aguentar, suportar, tolerar, deixar-se levar por, deixar-se con-vocar por. É ousado, como sempre em tais casos, traduzir páthos por dis-posição, palavra com que procuramos expressar uma tonalidade de humor que nos harmoniza e nos con-voca por um apelo. Devemos, todavia, ousar esta tradução porque só ela nos impede de representarmos páthos psicologicamente no sentido da modernidade. Somente se compreendermos páthos como dis-posição (dis-position) podemos também caracterizar melhor o thaumàzein, o espanto.

Dessa forma, ao traduzir o pathos grego pela Stimmung do alemão, Heidegger visava evitar qualquer redução objetivante ou psicológica de sua significação arcaica, mostrando que, pela disposição (que nada tem a ver com tonalidades psicológicas), o ser-no-mundo é radicalmente aberto (Heidegger, pp. 36 e 37) e convocado a deixar interpelar pelo mundo.

Vemos, assim, que bem além das significações habituais de "doença", "sofrimento", "padecimento", "passividade" e de "paixão", o pathos da pathologia remete fundamentalmente o ser-aí à sua disponibilidade de abertura, à tonalidade e evocação do ser (é preciso ter em mente que die Stimme, em alemão, significa "a voz") próprias a essa disposição, logo à sua irredutível condição de incompletude e de absoluta não identidade com qualquer representação de um suposto si-mesmo. Uma (psico)patologia do sujeito, para que possa escapar do risco de se tornar apenas mais uma nova forma de visão-de-mundo (Weltanschauung) e de pretensa sabedoria relativa à realização plena da vida humana (Eudemonia), deve metodológica e eticamente se ocupar da pathologia sob a perspectiva das vicissitudes ameaçando a abertura constitutiva do sujeito e dos impedimentos que este possa vir a ter na responsabilização pelo seu cuidado. Sob esse prisma, a (psico)patologia do sujeito é incompatível com qualquer forma de naturalização, objetivação ou de psicologização do pathos, assim como de prescrição de ideais de realização existencial.

Dito em outros termos, a pathologia decorrente do pathos grego é irredutível à mera naturalização da "doença" em termos biológicos. 
Correlativamente, a história da psicopatologia pode ser pontuada pelas diferentes conotações implícita ou explicitamente atribuídas pelos grandes autores ao decisivo radical "pathos".

\section{O papel organizador das categorias de "saúde" e de "doença" para a racionalidade médica e psiquiátrica}

De maneira quase espontânea, a cultura atual tende a ver nas noções de "doença" e de "saúde" as referências organizadoras decisivas da racionalidade médica. Com efeito, desde os primórdios da medicina hipocrática, bem como na tradição galênica e árabe que a introduziu na Europa, "doença" e "saúde" já constituíam os dois conceitos maiores dessa prática. Averroes, por exemplo, inicia seu célebre Livro das generalidades da Medicina, de 1161, justamente por uma reflexão sobre os fundamentos da arte médica. Segundo o grande médico muçulmano andaluz, "a [...] medicina é uma arte fundada em princípios verdadeiros, com a qual se busca a conservação da saúde do corpo humano e a eliminação da enfermidade, na maior medida que seja possível em cada um dos corpos" (Averroes, 1161/2003, p. 43).

Remetendo ao mal, ao sofrimento e à morte, a doença encarnaria com presteza o papel de inimigo estrangeiro ao eu a ser combatido. A imagem das doenças infecciosas aparece aqui como protótipo intuitivo desse tipo de representação. Tratar-se-ia, sob essa perspectiva, de um mal natural, exterior ao sujeito, mas de caráter invasivo, produzindo ruptura com um nível de funcionamento fisiológico supostamente ideal, o qual fora pacientemente alcançado pela espécie ao longo das eras - através da seleção natural. Tal estado ótimo de desempenho fisiológico expressaria a sabedoria própria à Natureza em relação aos seres vivos. A noção intuitiva de saúde brotaria assim, espontaneamente, por contraste com essa concepção de enfermidade.

Christophe Boorse em seu seminal artigo de 1977, intitulado "Health as a theoretical concept", anteriormente mencionado, sustenta que a concepção médica de "saúde" como ausência de doença é uma proposição isenta de caráter valorativo. Para isso, o conceito de "doença" deve ser definido como estado interno que diminui a capacidade do organismo para o desempenho de funções biológicas, mantendo-as com níveis de eficiência abaixo daqueles que são típicos da espécie. A tipicidade pode ser objetivamente determinada em termos estatísticos e o prejuízo da eficiência biológica se exprimiria na impossibilidade de realização de determinada função fisiológica em seus 


\section{EPISTEMOLOGIA DA PSICOPATOLOGIA}

níveis ótimos previstos para a espécie. Decorre daí que o tratamento visaria fundamentalmente, na medida do possível, a instauração/restauração desse estado ótimo de funcionamento fisiológico.

O célebre filósofo alemão Hans-Georg Gadamer investigou as consequências teóricas e clínicas de uma concepção naturalística do par conceitual saúde-doença. Para isso, em sua "Apologia da arte médica", de 1965, ele busca explicitar as fronteiras que separariam a tekhné médica da poiésis própria à arte, em um sentido estrito. Seu argumento coloca em evidência o fato de que na medicina

a ideia principal não é produzir uma formação artificial. O que a arte de curar deve produzir é a saúde, quer dizer, algo que é natural em si mesmo. Eis o que impõe o cunho a esta arte. Ela não é invenção e planificação de algo novo, de algo que não existe sob essa forma e cuja produção se procura, mas antes o princípio, uma espécie de fazer e conseguir, que não faz nada próprio nem de próprio. O seu saber e a sua capacidade subordinam-se completamente ao curso natural, ao procurar restabelecê-lo de tal forma que sua ação desapareça dentro do equilíbrio da saúde. O médico não pode distanciar-se da sua obra como qualquer artista pode fazer a respeito da sua. [...] A obra do médico, pelo contrário, justamente por se tratar da saúde, deixa por completo de ser sua. $\mathrm{Na}$ realidade nunca foi. (Gadamer, 1997, pp. 41-42)

Uma arte sem criação: eis uma paradoxal definição de medicina decorrente da concepção estritamente naturalística de saúde e de doença proposta por Gadamer.

Esta, contudo, deixa de fora elementos fundamentais da prática médica, que ficam progressivamente mais evidentes à medida que a medicina contemporânea se aproxima cada vez mais de um exercício clínico de bioengenharia humana, sendo o tratamento das doenças apenas um caso particular de sua atividade. O que dizer, por exemplo, de uma mulher que solicita a seu médico uma intervenção de natureza anticoncepcional, a qual em grande parte das vezes pode colocar em risco seu bom funcionamento fisiológico? Nesse caso, é justamente a excelente saúde reprodutiva de seu organismo que constitui sua "patologia", pois contradiz sua posição de sujeito de desejo que não quer engravidar. É para isso que ela busca tratamento. $\mathrm{Ou}$ ainda, daqueles procedimentos que visam intervir nos processos naturais de envelhecimento e morte, introduzindo artificialmente o prolongamento da saúde e da sobrevida individuais, eventualmente contraditórios com os interesses de sobrevivência da espécie? E as cirurgias estéticas? A dermatologia cosmética? E as intervenções médicas para aperfeiçoamento das performances esportivas? Cirurgias e procedimentos hormonais de 
redesignação de gênero? Ou mesmo, mais simplesmente, o que dizer do indivíduo que busca auxílio médico com o pedido explícito de alívio de um sofrimento ou cura de uma doença, mas que no íntimo deseja sobretudo obter o gozo paradoxal da posição de paciente, independentemente da realidade objetiva de seus males? (cf. Stanghellini \& Broome, 2014).

Em todos esses exemplos coloca-se a interrogação radical sobre o quê, em última instância, constitui "patologia" para alguém em posição de sujeito enquanto tal e, correlativamente, quais as diretrizes éticas e as finalidades últimas do tratamento médico? Tais reflexões podem colocar em evidência o fato de que a centralidade histórica da noção de "doença", desde o século XVII, pode ter funcionado como véu encobrindo a dimensão propriamente "patológica" da qual se ocupa a medicina.

\section{A crítica de Canguilhem à concepção ontológica da doença e suas consequências para a psicopatologia}

“Para agir é preciso ao menos localizar" (Canguilhem, 1966/1991, p. 11). 846 Com essa frase de amplas consequências, Georges Canguilhem inicia aquele que seria um dos escritos mais influentes para o pensamento contemporâneo sobre a medicina em suas relações com a patologia, $O$ normal e o patológico. Essa necessidade prática própria ao campo médico está, segundo o grande filósofo francês, na raiz daquilo que designou como "teoria ontológica da doença" (p. 11): ao localizarmos através da linguagem um "ser inimigo a ser combatido", corremos o risco de promover a ontologização da categoria criada, dando origem a uma "representação ontológica do mal", apta a parasitar todo o pensamento teórico e a própria atividade clínica. A doença, assim concebida, adquire artificialmente o estatuto de um ser em si, autônomo e consistente. Canguilhem situa explicitamente na obra de Thomas Sydenham (1624-1689) um marco histórico, assinalando o declínio das concepções dinâmicas e totalizantes relativas ao adoecer, próprias à tradição hipocrática e dominante até o século XVII na medicina europeia, dando lugar à ideia de que para ajudar de maneira eficaz o paciente "é necessário delimitar e determinar seu mal" (p. 13).

Instala-se, a partir daí, a visão que se tornaria hegemônica da doença como "espécie mórbida", que como tal precisa ser identificada, classificada e combatida: "il y a des espèces morbides comme il y a des espèces végétales ou animales" (existem espécies mórbidas, como existem espécies vegetais ou animais) (p. 13). Um novo paradigma racional e clínico passa, desde então, 


\section{EPISTEMOLOGIA DA PSICOPATOLOGIA}

a dominar o cenário intelectual não apenas da medicina, mas da cultura em geral. Em grande extensão, a obra de Canguilhem tem por objetivo a desconstrução dessa mentalidade, propondo em contrapartida a ideia de que a normatividade biológica é sempre individual, devido à "relatividade do normal ao meio no qual o indivíduo se encontra e da natureza social e cultural do ambiente humano" (Giroux, 2012, p. 24. A tradução desse trecho é de minha autoria), de tal maneira que "o problema do patológico no homem não poderia se limitar ao biológico" (Ibid.).

A questão que se coloca, então, de maneira premente, pode ser assim formulada: o que confere o estatuto propriamente (psico)patológico ao padecer humano, naquilo que este é irredutível à mera expressão sintomatológica da doença?

\section{A emergência da questão do sujeito do coração do debate psicopatológico}

No campo psiquiátrico, o estatuto teórico atribuído à "patologia" quando esta é referida ao "mental" sempre foi objeto de grandes controvérsias. Em uma perspectiva cartesiana, tão própria à medicina dita ocidental, como é possível que a doença, entidade concebida em termos naturais, logo segundo as modalidades de existência próprias à res extensa, incida sobre a mente, paradigma mesmo da res cogitans? Apresenta-se, de antemão, na própria definição do objeto da psicopatologia - a doença mental - uma possível contradição interna. Os termos do problema são claramente colocados por Kurt Schneider já nas primeiras páginas de seu célebre tratado Psicopatologia clínica:

O conceito de enfermidade é para nós, principalmente na Psiquiatria, um conceito rigorosamente médico. Enfermidade em sentido próprio existe apenas na esfera somática, e só chamamos as anomalias psíquicas de "mórbidas" quando podem ser reconduzidas a processos orgânicos mórbidos. Denominar de mórbidas manifestações psíquicas ou puramente sociais sem este fundamento é apenas uma imagem e não possui, portanto, nenhum valor científico. [...] Destarte, em Psiquiatria, fundamos o conceito de enfermidade exclusivamente em alterações mórbidas do corpo. (Schneider, 1948/1976, pp. 29-30)

Dessa forma, ao operar com conceitos psicopatológicos fundamentais tão frágeis como o de "doença mental", a psiquiatria deixava flanco aberto às críticas mais contundentes, colocando em xeque sua própria legitimidade como prática médica. Foi assim que um dos grandes representantes da 
antipsiquiatria, Thomas Szasz, atacou as pretensões da especialidade a integrar de pleno direito o campo da medicina. Em um artigo publicado em 1960, significativamente intitulado "O mito da doença mental" (fórmula que seria novamente empregada em 1974 como título de seu livro mais conhecido), esse combativo psiquiatra húngaro-americano atacava a credibilidade teórica da psiquiatria com os seguintes argumentos:

"Is there such a thing as mental illness?" and to argue that there is not. [...] Mental illness, of course, is not literally a "thing" — or physical object — and hence it can "exist" only in the same sort of way in which other theoretical concepts exist. (Szasz, 1960, p. 113)

É assim que, para Szasz, a suposta noção de "doença mental" não passaria de um "mito". Trata-se, a seus olhos, de uma mera abstração; no melhor dos casos, de uma má metáfora, uma vez que os critérios de definição das ditas "doenças mentais" seriam puramente éticos e sociais e não médicos, no sentido estritamente biológico pelo qual Szasz concebe a Medicina. Vemos assim a insistência da questão da qual nos ocupamos neste estudo: que estatuto atribuir ao pathos que designa a (psico)patologia?

Ainda que de imensa importância, a naturalização da patologia, reduzindo-a ao estatuto de "doença" em um sentido estritamente biológico, constitui apenas uma das múltiplas modalidades de delimitação teórica do "patológico" em medicina e em psiquiatria. Diferentes concepções teóricas da "patologia" competem pela primazia epistemológica nesses campos, conhecendo diferentes momentos históricos de hegemonia na conquista de corações e mentes de cientistas, filósofos da ciência, de clínicos, pacientes e da cultura em geral.

É assim que, tradicionalmente na filosofia da medicina, duas grandes perspectivas teóricas relativas aos conceitos de "saúde" e de "doença" são dominantes nesse debate. Surgindo em tempos relativamente recentes, a investigação teórica sistemática sobre o estatuto da noção de "patologia" encontra em Canguilhem a figura de um pioneiro. Rompendo com o que chamava de "dogma positivista", dominante no campo médico, o autor de $O$ normal e o patológico defendia "a relatividade individual da saúde e a impossibilidade consecutiva de uma definição objetiva e absoluta do normal" (Giroux \& Lemoine, 2012, p. 7). Ora, a perspectiva médica atualmente dominante a respeito da doença tem pretensões à naturalidade e à objetividade. Foi se insurgindo contra o relativismo de noções como a de "normatividade biológica individual" de G. Canguilhem, que autores como Boorse, anteriormente evocado, ou Nordenfelt virão a propor a 


\section{EPISTEMOLOGIA DA PSICOPATOLOGIA}

existência de um conceito naturalista, objetivo e científico de doença. Por outro lado, os chamados "normativistas", como Engelhardt, estarão mais preocupados com a pragmática da ação médica. Para estes, a noção de "doença" é intrinsecamente normativa, devendo ser considerada mero recorte linguístico de estados objetiváveis da realidade clínica, capazes de funcionar como suportes e orientadores para uma intervenção médica eficaz. Jerome Wakefield, com seu célebre conceito de harmful dysfunction (Wakefield, 1922), ocupa uma posição intermediária nesse debate entre naturalistas e normativistas, sustentando uma espécie de normativismo híbrido. ${ }^{7}$ É importante lembrar que as posições de Wakefield constituem as mais importantes referências teóricas na elaboração do conceito fundamental de "mental disorder", atualmente empregado em classificações psiquiátricas como o DSM-5. De fato, verificamos o vigor da tensão entre posições normativistas e naturalistas na psiquiatria contemporânea na disputa pela hegemonia nos terrenos do diagnóstico e da nosografia travada entre o normativismo do DSM e o ideal naturalista expresso pelo RDoC (cf. Pereira, 2014).

O resgate que aqui fazemos dos diferentes posicionamentos teóricos em face do estatuto do "patológico" em psiquiatria deve nos auxiliar a conceber toda a complexidade dos esforços visando a separação formal dos registros nosográfico (diagnóstico e classificação), nosológico (perturbações de natureza biológica relacionadas ao transtorno) e especificamente psicopatológico (relativo aos impasses - relacionados ou não aos dois registros precedentes - prejudicando ou mesmo impedindo a realização do sujeito enquanto ser de linguagem e de fala). Tal esforço para a delimitação

${ }^{7}$ Em outro trabalho, sumarizei as posições de Wakefield nos seguintes termos:

"Segundo essa teoria, a noção de transtorno mental (mental disorder) só poderia ser legitimamente empregada se uma condição psíquica respondesse a duas exigências. A primeira seria de caráter objetivo e factual: haveria uma alteração da função mental que, segundo o autor, teria sido selecionada pela seleção natural como a mais eficiente para a sobrevivência da espécie. Em outros termos, a noção de "dysfunction" garantiria a ancoragem do conceito de mental disorder em um terreno de ciências naturais. O segundo elemento teria uma dimensão valorativa e contextual: a alteração decorrente dessa disfunção deveria ser subjetiva e socialmente considerada como prejudicial ao indivíduo. Vemos assim articulados fatos objetiváveis e valores humanos em um único conceito. Essa famosa concepção híbrida do transtorno mental constituiria a base para a legitimidade médica e social das nosologia e nosografia psiquiátricas" (Pereira, 2014, p. 1047). 
desses campos sempre se deu de forma contínua, mas claudicante e sempre precária na história da psiquiatria.

É assim que em suas origens, a psiquiatria francesa de Pinel e de Esquirol tinha como perspectiva principal a organização descritiva do campo das perturbações psíquicas, associada a um primeiro esforço classificatório. Sem assumir qualquer compromisso apressado com a definição de entidades mórbidas específicas (no sentido estrito de doenças médicas), esses pioneiros da abordagem psiquiátrica da loucura buscavam realizar de maneira sistemática o indispensável trabalho preliminar de descrição e ordenamento das situações clínicas típicas mais frequentemente observadas. As categorias assim descritas tinham um estatuto mais estritamente nosográfico do que propriamente nosológico ou psicopatológico. Será apenas posteriormente, com a obra de Jean-Pierre Falret, que as perturbações mentais descritas na experiência psiquiátrica teriam o estatuto mais formalmente nosológico de entidades mórbidas.

Na tradição alemã, um autor como Wilhelm Griesinger inscreveria a psiquiatria de maneira mais clara na hegemonia naturalista dominante na medicina em geral ao sustentar posições epistemológicas e clínicas sintetizadas em sua fórmula: "Doenças mentais são doenças cerebrais". Kraepelin se inscreve nessa mesma tradição, mas assume posturas metodológicas mais parcimoniosas. Seu objetivo principal era a descrição precisa do caso clínico em sua patoplastia atual e em sua evolução típica ao longo do tempo. Segundo esse célebre psiquiatra alemão, todo esforço de delimitação nosológica das entidades mórbidas das quais se ocupa sua especialidade, depende desse trabalho descritivo e classificatório prévio.

Mais ou menos ao mesmo tempo, Freud, com sua nascente psicanálise e, em especial, ao conceber uma "psicopatologia da vida quotidiana", ou seja, uma condiçao envolvendo perturbações do pathos de um sujeito, sem qualquer relação necessária com a categoria doença, introduz um corte na hegemonia do discurso médico-biológico, o qual tendia a borrar de fato as fronteiras separando patologia e nosologia. Doravante seria concebível se pensar o (psico)patológico de forma específica em relação ao plano propriamente biológico do padecer psíquico.

Ludwig Binswanger, psiquiatra formado por Bleuler em Zurique e discípulo de primeira hora de Freud, desempenhará um papel fundamental no campo de questões de que aqui nos ocupamos. Ao de seu próprio percurso, as posições de Binswanger relativas à psicopatologia, em suas incidências teóricas e clínicas, foram tomando diferentes matizes e orientações, sempre mantendo sua inscrição no campo especificamente psiquiátrico. Assim, ele passa de uma concepção marcantemente freudiana relativa ao adoecimento 


\section{EPISTEMOLOGIA DA PSICOPATOLOGIA}

psíquico, para uma abordagem fenomenológica original, em relação àquela proposta por Jaspers. Em seguida, fortemente marcado por Ser e tempo e pela Daseinanalytik de Heidegger, Binswanger será o grande iniciador da chamada Análise existencial, com incidências tanto no campo psicopatológico quanto na concepção terapêutica da psiquiatria. No final da vida, em uma postura mais ancorada pela tradição clínica psiquiátrica e pelo pensamento de Husserl, Ludwig Binswanger retomará uma abordagem da psicopatologia mais próxima da fenomenologia. Apesar de todas essas mudanças de posição ao longo de sua trajetória, em cada momento o grande psiquiatra suíço manteve-se fiel à ideia de que o campo especificamente psicopatológico não representava uma mera extensão sintomática de perturbações cerebrais subjacentes, ${ }^{8}$ devendo ser abordado com métodos que levassem em conta a condição propriamente humana do nível psicopatológico do padecer psíquico.

Muitos psiquiatras, psicanalistas e filósofos foram profundamente influenciados pelo pensamento e pela prática clínica de Binswanger em psicopatologia e em psiquiatria. Entre eles podemos mencionar Minkowski, Lacan, Roland Kuhn, Henri Maldiney, Pierre Fédida e Jacques Schotte.

Kuhn, psiquiatra de consistente formação filosófica e descobridor dos efeitos antidepressivos da imipramina, apoia-se em sua leitura e interlocução com Binswanger para conceber os efeitos da psicofarmacologia em psiquiatria, a partir de uma abordagem analito-existencial tanto da psicopatologia quanto do próprio processo terapêutico mediado pela medicação e com vistas psicoterápicas.

Henri Maldiney, por sua vez, filósofo inclassificável em qualquer tradição filosófica específica, estuda de maneira sistemática a tradição não médica ligada ao pathos grego, em particular na filosofia e na tragédia. É a ele que devemos o chamado resgate da dimensão trágica do pathos, através de seu comentário da expressão pathei mathos, proclamada pelo coro que testemunhava a hybris e o caráter impenitente do protagonista, Agamenon, na tragédia de Ésquilo: "Ele [Zeus] abriu aos homens as vias da prudência dando lhes como lei: 'Sofrer para aprender' [pathei mathos]. Quando no meio do sono, sob o olhar do corpo, o doloroso remorso retorna, a sabedoria neles, apesar deles, penetra. E eis aí, creio, a violência benfazeja dos deuses sentados no timão celeste!"

${ }^{8}$ É preciso guardar em mente o fato de que Binswanger foi, ao longo de toda sua carreira, um ferrenho crítico de toda abordagem em psicopatologia que estivesse fundamentada na ideia de que o transtorno mental incidiria em um Homo natura e não sobre um ser humano tomado enquanto tal. 
Maldiney identifica aqui uma tradição que surge com os gregos, e, sobretudo, com o teatro de Ésquilo, a qual vê no pathos um sofrimento, que é ao mesmo tempo uma paixão, comportando a possibilidade de se transformar em sabedoria (pathei mathos), à condição de poder ser escutado por um outro, capaz de sustentar a palavra do sofredor até que esta atinja seus extremos, propiciando elaboração e um novo autoengendramento, enriquecido pela integração da experiência patológica, do próprio sujeito (cf. Pereira, 1998).

Pierre Fédida tomaria amplamente recurso nesse comentário de Maldiney para delimitar sua "Psicopatologia Fundamental". Assim, já em seu livro Le corps du vide et espace de séance, de 1977, encontramos a seguinte reflexão em seu capítulo de conclusão, intitulado justamente "Projeto de uma psicopatologia somática":

Devemos dizê-lo claramente: o projeto de uma psicopatologia, que ela seja fenomenológica ou psicanalítica - se subtrai radicalmente à ideologia médica ou medicalizada de uma 'patologia mental' e mesmo de uma "patologia psíquica". A revolução interna engajada por uma psicopatologia assim concebida modifica as relações de equilíbrio e de troca com a biologia clínica. Mas sobretudo ela concerne esta questão primordial: o que pode significar pathos quando psychè constitui o prefixo de seu sentido? (Fédida, 1977, p. 357)

Aqui, Fédida acrescenta uma nota de rodapé em que faz sua primeira referência ao pathei mathos de Ésquilo, retirado de um artigo de Maldiney, onde esse autor declara: "Mas se, segundo a expressão de Ésquilo, pathei mathos, o homem é um ser a quem o sofrimento ensina, é preciso que ele seja capaz de acolher este ensinamento e que esse aí onde ele é experimentado, ele o faça existir. Mesmo passivo, diz Maldiney, ele não pode estar aí presente senão se mantendo, mesmo em sua passividade, na dianteira de si mesmo. Não existe provação significante senão para uma liberdade" (Pereira, 2009, p. 267).

Fédida tomaria igualmente apoio na obra de Viktor von Weizsaecker, autor decisivo na concepção de psicopatologia desenvolvida pelo grande autor francês (cf. Fédida, 1998). Em seu livro derradeiro, Pathosophie, publicado em 1956, o médico alemão, correspondente de Freud, explicita a relação intrínseca e decisiva existente entre "patologia" e "sujeito", colocando a questão em termos éticos e metodológicos, com consequências clínicas: "[...] o homem é algo que tem um sujeito e é essa subjetividade que faz obstáculo a todo enunciado objetivo" (von Weizsaecker, 1956/2011, p. 11). É assim que, sob o ângulo da prática clínica, von Weizsaecker considera que: "É indispensável separar o conhecimento objetivo da ação moral, se assumirmos que o universo do primeiro é necessariamente lógico e, portanto, previsível, 


\section{EPISTEMOLOGIA DA PSICOPATOLOGIA}

ao passo que o universo do segundo é essencialmente noturno e, portanto, totalmente indecidível" (cf. Célis, 2007, p. 6). Torna-se, pois, imperativo, aos olhos de Weizsäcker, integrar a subjetividade do paciente na realidade objetiva a ser tratada, ainda que reconheça e advirta que "A filosofia moral alerta contra qualquer pretensão de conhecer o indivíduo" (p. 6).

Dessa forma, a ética médica de Viktor von Weizsäcker constitui uma reversão epistemológica visando re-definir o estatuto da atividade clínica. Essa reversão não pretende negar a necessidade para a Medicina de extrair seus recursos operacionais das chamadas ciências fundamentais (biologia, fisiologia, ...). Seu objetivo é colocar o paciente no centro da atividade terapêutica, focalizando os possíveis desequilíbrios entre seu ambiente e ele próprio, que atuam na doença subjacente.

O panorama que aqui traçamos dos debates no campo psicopatológico permitindo localizar e conceber mais precisamente a emergência da questão do sujeito no coração mesmo da interrogação sobre o que constitui para o homem, em posição de sujeito, sua patologia.

O próximo passo de nosso projeto consistirá, pois, na retomada da questão do sujeito como referente central da (psico)patologia, dessa vez com o auxílio da concepção de sujeito decorrente das obras psicanalíticas de Freud e de Lacan. Este, como inicialmente anunciado, será o tema da parte II do presente estudo.

\section{Referências}

Aristóteles (2008). Metafísica I-II-III (Alpha- $\alpha$-Beta). (Lucas Angioni, trad.). Clássicos da Filosofia: Cadernos de Tradução, IFCH-UNICAMP, 15.

Averroes (2003). El libro de las generalidades de la medicina. Madri, España: Editorial Trotta. (Trabalho original publicado em 1161).

Bernard, C. (1865). Introduction à l'étude de la médecine expérimentale. Paris, França: J.-B. Ballière et Fils.

Berrios, G.E. (2016, jun.). Introdução ao pensamento de Gustav Störring. Revista Latinoamericana de Psicopatologia Fundamental, 19(2), 303-310.

Binswanger, L. (1956). Três formas de existência malograda - extravagância, excentricidade, amaneiramento. Rio de Janeiro, RJ: Zahar, 1977.

Boorse, C. (1977). Health as a theoretical concept. Philosophy of science, 44, 542-573 . 
Canguillem, G. (1991). Le normal et le pathologique ( $3^{\mathrm{e}}$ ed.). Paris, France: PUF. (Trabalho original publicado em 1966).

Célis, R. (2007). L'étique médicale et clinique de Viktor von Weizsäcker. Parte I: Prolégomènes épistémologiques. Parte II: Les fondements anthropologiques de l'éthique médicale. Revue Étique, questions de vie. Janvier 2007, 1-26.

Chaslin, Ph. (1912). Éléments de sémiologie et de clinique mentale. Paris, França: Asselin et Houzeau.

Entralgo, P. L. (1970). La medicina hipocrática. Madrid, España: Ediciones de la Revista de Occidente.

Fédida, P. (1977). Le corps du vide et espace de séance. Paris, France: Editions Universitaires.

Fédida P. (1998, set.). De uma psicopatologia fundamental - Nota sobre a noção de paradigma. Revista Latinoamericana de Psicopatologia Fundamental, I(3), 102-121.

Feys, J.-L. (2009). L'anthropopsychiatrie de Jacques Schotte. Une introduction. Paris, France: Editions Hermann.

Gadamer, H.-G. (1997). Apologia da arte de curar. In H.-G. Gadamer, O mistério da saúde: o cuidado da saúde e a arte da medicina. Lisboa, Portugal: Edições 70.

Giroux, E. (2012). Introduction au texte de Georges Canguilhem: Le normal et le pathologique. In E. Giroux, \& M. Lemoine, Philosophie de la médecine: santé, maladie, pathologie (pp. 23-27). Paris, France: Librairie philosophique J. Vrin.

Giroux, E., \& Lemoine, M. (2012). Introduction. In E. Giroux, \& M. Lemoine, Philosophie de la médecine: santé, maladie, pathologie (pp. 7-21). Paris, France: Librairie philosophique J. Vrin.

Heidegger, M. (2002). A questão da técnica. In M. Heidegger, Ensaios e conferências (Ernildo Stein, trad., pp. 27-40). Petrópolis, RJ: Vozes. (Trabalho original publicado em 1953).

Heidegger, M. (2005). Qu'est-ce que la philosophie? (Ernildo Stein, trad., pp. 27-40). Rio de Janeiro, RJ: Nova Cultural. (Trabalho original publicado em 1955).

Heidegger, M. (2009). Seminários de Zollikon (2a ed. rev.). Petrópolis, RJ: Vozes/ Bragança Paulista, SP: Editora Universitária São Francisco.

Jaeger, W. (1995). Paideia - A formação do homem grego. São Paulo, SP: Martins Fontes.

Jaspers, K. (1959a). Allgemeine Psychopathologie ( $7^{\text {a }}$ ed.). Berlin. Alemanha: Springer Verlag. (as traduções são de responsabilidade de G. Messas)

Jaspers, K. (1979). Psicopatologia Geral. Rio de Janeiro, RJ: Atheneu. (Trabalho original publicado em 1913).

Kant, I. (2011). Crítica da razão prática. São Paulo, SP: Martins Fontes.

Lacan, J. (1988). O seminário. Livro VII. A ética da psicanálise. Rio de Janeiro, RJ: 


\section{EPISTEMOLOGIA DA PSICOPATOLOGIA}

Jorge Zahar. (Trabalho original publicado em 1959-1960).

Maldiney, H. (1961). Comprendre. Revue de Métaphysique et de Morale, 66(1/2), 35-89.

Martins, F. (1999, dez.). O que é pathos? Revista Latinoamericana dePsicopatologia Fundamental, $I I(4), 62-80$.

Messas, G. P. (2014). O sentido da fenomenologia na Psicopatologia Geral de Karl Jaspers. Psicopatologia Fenemenológica Contemporânea, 3, 23-47.

Mezzich, J. et al. (2003). Essentials of the World Psychiatric Associations's International Guidelines for Diagnostic Assessment (IGDA), The British Journal of Psychiatry, supplem.

Pereira,M. E. C. (1998, mar.). Formulando uma psicopatologia fundamental. Revista Latinoamericana de Psicopatologia Fundamental, I(1), 60-76.

Pereira, M. E. C. (2009, jun.). Pathos, violence and power: the ethical implications of Fundamental Psychopathology. Revista Latinoamericana de Psicopatologia Fundamental, 12(2), 263-284. Disponível em: <https://dx.doi.org/10.1590/S1415$47142009000200002>$.

Pereira, M. E. C. (2014). A crise da psiquiatria centrada no diagnóstico e o futuro da clínica psiquiátrica: psicopatologia, antropologia médica e o sujeito da psicanálise. Physis - Revista de Saúde Coletiva, 24(4), 1035-1052.

Pereira, M. E. C. (2017). Freud, o sujeito da psicopatologia e o futuro da psiquiatria. In D. Kuppermann (Org.), Por que Freud, hoje? (pp. 167-190). São Paulo, SP: Zagodoni, 2017.

Platão (1991). O Banquete. In Platão (Os Pensadores) (pp.7-53). São Paulo, SP: Nova Cultural.

Rocha, Z. (2004). Heráclito de Éfeso, filósofo do Logos. Revista Latinoamericana de Psicopatologia Fundamental, 7(4), 7-31. Disponível em: <http://www.scielo. br/pdf/rlpf/v7n4/1415-4714-rlpf-7-4-0007.pdf>.

Schneider, K. (1976). Psicopatologia clínica. São Paulo, SP: Mestre Jou. (Trabalho original publicado em 1948).

Stanghellini, G. (2013). The ethics of incomprehensibility. In G. Stanghellini, \& T. Fuchs (Eds.), One century of Karl Jaspers' general psychopathology (pp. 166-181). Oxford: Oxford University Press.

Stanghellini, G., \& Broome, M. (2014). Psychopathology as the basic science of psychiatry (Editorial). The British Journal of Psychiatry, 205, 169-170. doi: 10.1192/bjp.bp.113.138974

Szasz, T. (1960). The myth of mental illness. American Psychologist, 15, 113-118.

Von Weizsaecker, V. (2011). Pathosophie. Grenoble, France: Jérôme Millon. (Trabalho original publicado em 1956).

Wakefield, J. C. (1992). The concept of mental disorder. On the boundaries between biological facts and social values. The American Psychologist, 476(3), 373-388. 


\section{Resumos}

(Project of a (psycho)pathology of the subject (I): Redefinition of the concept of Psychopathology in light of the subject issue)

This paper proposes the theoretical bases for the elaboration of a new definition for Psychopathology, conceiving it as the study of the morbid impasses disturbing, or even preventing, the realization of a singular subject within the social bond. The notion of subject at issue is the one arising from the psychoanalytic thinking of Freud and Lacan.

The (psycho)pathology of the subject relies on the ideas of Viktor von Waizsaecker, for whom "pathology", unlike the biological notion of "disease", is a phenomenon that presupposes a subject as such. It is also inspired by Pierre Fédida's work, which claims that psychopathology refers fundamentally to the subjective pathos, in its multiple semantic dimensions of passivity, suffering and passion.

The consequences of the redefinition of the (psycho)pathology proposed here apply to the set of clinical practices, either medical-psychiatric or others, through the ethical and technical specification of the treatment, now guided by the care with the possible and responsible realization of the subject as a language being, inside the social bond.

Key words: Subject, psychopathology, psychoanalysis, psychiatry

(Project d'une (psycho)pathologie du sujet (I): Redéfinition du concept de Psychopathologie à la lumière de la question du sujet

Cette étude aborde les bases théoriques pour l'élaboration d'une nouvelle définition de psychopathologie, en la concevant comme l'étude des impasses morbides perturbant, voire même empêchant, la réalisation d'un sujet singulier au sein du lien social. La notion de sujet en question est celle découlant de la pensée psychanalytique de Freud et de Lacan.

La (psycho) pathologie du sujet repose sur les idées de Viktor von Waizsaecker, pour qui la "pathologie », contrairement à la notion biologique de " maladie ", est un phénomène qui présuppose un sujet en tant que tel. Il s'inspire également de l'œuvre de Pierre Fédida, qui soutient que la psychopathologie renvoie fondamentalement au pathos subjectif, dans ses multiples dimensions sémantiques de passivité, de souffrance et de passion.

Les conséquences de la redéfinition de la (psycho) pathologie proposée ici portent sur l'ensemble des pratiques cliniques, qu'elles soient psychanalytiques, médico-psychiatriques ou autres, au travers de la spécification éthique et technique du traitement, désormais guidé par les soins avec réalisation possible et responsable, du sujet en tant qu'être de langage, à l'intérieur du lien social.

Mots clés: Sujet, psychopathologie, psychanalyse, psychiatrie 


\section{EPISTEMOLOGIA DA PSICOPATOLOGIA}

(Proyecto de una (psico)patología del sujeto (I): Redefinición del concepto de Psicopatología a la luz de la cuestión del sujeto)

Este artículo propone la base teórica para la elaboración de una nueva definición de Psicopatología, concibiéndola como el estudio de las calamidades mórbidas que perturban o incluso impiden la realización de un sujeto singular dentro del lazo social. La noción de sujeto aqui en cuestión es la que surge del pensamiento psicoanalítico de Freud y de Lacan.

La (psico)patología del sujeto se basa en las ideas de Viktor von Waizsaecker, para quien la "patología", a diferencia de la noción biológica de "enfermedad", es un fenómeno que implica a un sujeto como tal. También está inspirada en el trabajo de Pierre Fédida, que sostiene que la psicopatología se refiere fundamentalmente al pathos subjetivo en sus múltiples dimensiones semánticas de pasividad, sufrimiento y pasión.

Las consecuencias de la propuesta de redefinición de la (psico)patología repercuten sobre el conjunto de prácticas clínicas, ya sean psicoanalíticas o médicopsiquiátricas, entre otras, a través de la especificación ética y técnica del tratamiento, ahora guiado por la preocupación con relación a la realización posible y responsable del sujeto como ser de lenguaje dentro del lazo social.

Palabras clave: Sujeto, psicopatología, psicoanálisis, psiquiatría

(Projekt einer (Psycho)Pathologie des Subjekts (I): Neudefinition des Begriffs der Psychopathologie im Licht der Frage des Subjekts

Diese Arbeit schlägt die theoretische Grundlage für die Ausarbeitung einer neuen Definition der Psychopathologie vor, die als Untersuchung krankhafter Sackgassen aufgefasst wird, die die Verwirklichung eines einzelnen Subjekts innerhalb der sozialen Bindung stören oder sogar verhindern. Der hier untersuchte Begriff des Subjekts basiert auf den psychoanalytischen Überlegungen von Freud und Lacan.

Die (Psycho)Pathologie des Subjekts beruht auf den Ideen von Viktor von Waizsaecker, für den „Pathologie“ im Gegensatz zum biologischen Begriff „Krankheit" ein Phänomen ist, das ein Subjekt als solches voraussetzt. Der Begriff basiert sich außerdem auf Pierre Fédidas Arbeit, in der behauptet wird, die Psychopathologie beziehe sich in ihren vielfältigen semantischen Dimensionen von Passivität, Leiden und Leidenschaft grundsätzlich auf das subjektive Pathos.

Die Konsequenzen der hier vorgeschlagenen Neudefinition der (Psycho) Pathologie betreffen alle klinischen Praktiken, einschließlich die psychoanalytische, medizinisch-psychiatrische und die anderen und zwar durch die ethische und technische Spezifikation der Behandlung, die sich nun mit Sorgfalt am Subjekt orientiert, das als Sprechwesen innerhalb der sozialen Bindung definiert wird.

Schlüsselwörter: Subjekt, Psychopathologie, Psychoanalyse, Psychiatrie 
Citação/Citation: Pereira, M. E. C. (2019, dez.). Projeto de uma (psico)patologia do sujeito (I): redefinição do conceito de psicopatologia à luz da questão do sujeito. Revista Latinoamericana de Psicopatologia Fundamental, 22(4), 828-858. http://dx.doi.org/10.1590/ 1415-4714.2019v22n4p828.10.

Editores/Editors: Profa. dra. Ana Maria R. G. Oda

Submetido/Submitted: 3.11.2019 / 11.3.2019 Aceito/Accepted: 5.11.2019 / 11.5.2019

Copyright: (C) 2009 Associação Universitária de Pesquisa em Psicopatologia Fundamental/ University Association for Research in Fundamental Psychopathology. Este é um artigo de livre acesso, que permite uso irrestrito, distribuição e reprodução em qualquer meio, desde que o autor e a fonte sejam citados / This is an open-access article, which permits unrestricted use, distribution, and reproduction in any medium, provided the original authors and sources are credited.

Financiamento/Funding: Este trabalho não recebeu apoio / This work received no funding.

Conflito de interesses/Conflict of interest: $\mathrm{O}$ autor declara que não há conflito de interesses. / The author declares that there is no conflict of interest.

\section{Mario Eduardo Costa Pereira}

Psiquiatra; Psicanalista; Professor titular de Psicopatologia Clínica pelo Laboratoire de Psychopathologie Clinique et Psychanalyse da Aix-Marseille Université (França); Livre-Docente em Psicopatologia do Departamento de Psicologia Médica e Psiquiatria da Faculdade de Ciências Médicas da Universidade Estadual de Campinas - Unicamp (Campinas, SP, Br), onde dirige o Laboratório de Psicopatologia: Sujeito e Singularidade (LaPSuS); Diretor do Núcleo de São Paulo do Corpo Freudiano - Escola de Psicanálise.

Rua Tessália Vieira de Camargo, 126 - Cidade Universitária "Zeferino Vaz"

13083-887 Campinas, SP, Br.

marioecpereira@uol.com.br

https://orcid.org/0000-0002-7975-8863

This is an open-access article, which permits unrestricted use, distribution, BY-NC and reproduction in any medium for non-commercial purposes provided the original authors and sources are credited. 